\title{
High hopes for Russia's nanotech firms
}

\section{But an ambitious government initiative has been slow to incubate a domestic high-tech industry.}

\section{MOSCOW}

Russia's investment in the very small is about to get bigger. The government announced this month that it is injecting 318 billion roubles (US\$11 billion) into its ambitious plan to develop and commercialize nanotechnologies.

Over the past two years, the Russian government has spent nearly 94 billion roubles on the effort. The goal is to establish a self-supporting domestic high-tech industry by 2015, to help reduce the country's dependence on oil and gas exports. But so far the project has created only 2,000 or so new jobs and a small number of public-private ventures.

"There has been little success so far," Russian president Dmitry Medvedev said at the opening of the International Nanotechnology Forum in Moscow on 6 October. "But we do have the knowledge, the financial resources and the administrative capacity to become leaders in a technological process that will change the world."

The financial crisis has sharpened the impetus for Russia to diversify its industries. Oil and gas prices dropped and foreign investment in Russia plunged by $31 \%$ between the first half of 2008 and the first half of 2009.

Russia's ambitious nanotechnology initiative became federal law in 2007 after Mikhail Kovalchuk, director of the Kurchatov Institute in Moscow, convinced then-President Vladimir Putin of the economic potential of the burgeoning field (see Nature 448, 233; 2007). Business analysts Lux Research expect global revenue from nanotechnology products to increase tenfold, from US $\$ 250$ billion to $\$ 2.5$ trillion, over the next 5-6 years; applications range from cosmetics and innovative drugs to low-friction coatings and environmental sensors.

Russia is catching up with other world leaders in its public investment in nanotechnol-

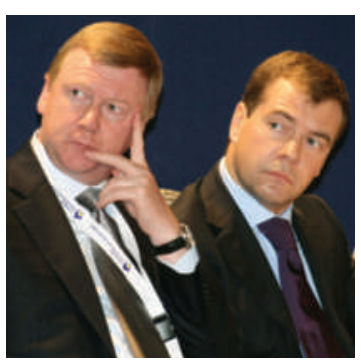

President Dmitry Medvedev (right) and Rusnano's chief executive, Anatoly Chubais.

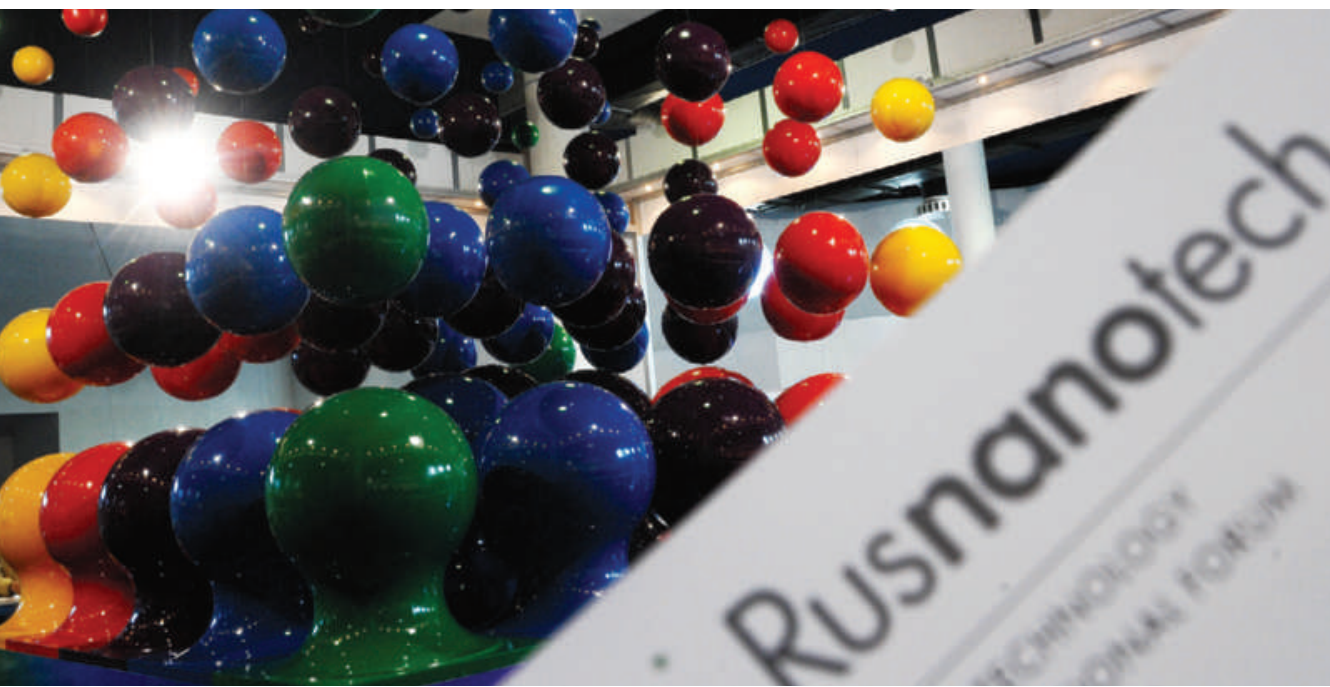

Exhibits at a major nanotech forum in Moscow this month highlighted the field's economic potential.

By 2015, Rusnano aims to have attracted 450 billion roubles in private capital, and generated sales of 900 billion roubles, chief executive Anatoly Chubais told the Moscow conference. "We are still in the valley-of-death curve" between product development and commercialization, he says. "But our newborn baby is growing nicely."

But business analysts remain sceptical as to whether the corporation will be able to meet its goals. "We're seeing a real and serious commitment to making Russian industry more innovative," says Michael Holman, an analyst with Lux Research in New York. "I'm impressed by the steps they have taken. But it's nonetheless going to be an uphill struggle, not least because foreign investors are not always comfortable with doing business in Russia."

Russia's nanotechnology work, in its broadest definition, involves 400 or so academic science departments and some 200 ogy (see graph), but it is still a minor player in making products. At current exchange rates, domestic sales and exports of Russian-made nano-enabled products are estimated at $\$ 4$ billion to $\$ 5$ billion for 2009 - no more than $2 \%$ of the global market volume.

Tasked with changing that is the stateowned venture-capital company, the Russian Corporation of Nanotechnologies (Rusnano). companies, says Leonid Gokhberg, an expert on econometrics at the Higher School of Economics in Moscow. The weakness of Russia's science system, which bars most university academics from applying for research funding and doesn't encourage entrepreneurial activity, is a barrier to efficient technology transfer, he says.

Creating decent business conditions and a more competitive academic environment is the next challenge, Medvedev told the nanotechnology forum. To that end, Rusnano says that it will lessen the initial investment risk for entrepreneurs by signing on as a co-investor, minority shareholder or supplier of cheap loans. In such joint ventures, any profits would be shared between the project applicant, the private investor and Rusnano, but Rusnano will claim no ownership or intellectual-property rights.

\section{On the right track}

Since its creation, Rusnano has received 1,200 project proposals, but most have not met its requirements. "At first, few people understood what we are looking for," says biologist Sergey Kalyuzhnyi, one of Rusnano's board members and director of its department for technical expertise. "In most cases we had to say 'sorry guys, nice idea, but not enough demonstration of market potential."

But awareness is increasing, he says. After a two-stage review process, Rusnano has now selected 36 projects for funding, all of which

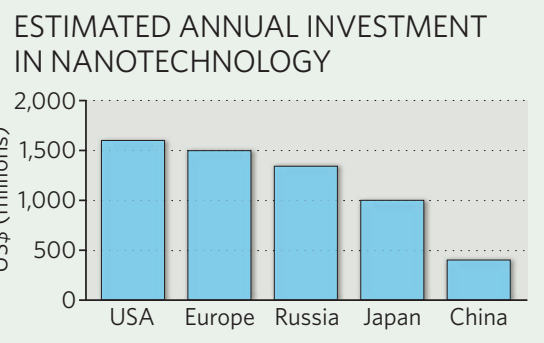


involve commercial production at manufacturing facilities in Russia. They include the Novosibirsk-based company Sun Innovations, which produces nano-ink for printers, and Rybinsk-based Saturn, which makes nano-structured coatings for use in aircraft.

Russia is also keen to attract international partners, which has proved difficult. Only two projects involving foreign partners have been approved so far, including a 1.1-billion-rouble joint venture with the German firm VI Systems in Berlin. The company, which develops laser-based components for ultra-high-speed computers, networks and interconnects, will start production in 2011 at a newly built facility in St Petersburg.

"It's a perfect match for us," says company founder Nikolay Ledentsov, a physicist formerly with the Ioffe Physical Technical Institute in St Petersburg. VI Systems currently manufactures its devices in Taiwan and elsewhere. "In the future we can safely produce in Russia, itself an emerging market for electronics, and share profits," he says.

Rusnano is also participating in joint infrastructure projects with firms such as RusChemBio, a Moscow-based 24-hour delivery service that supplies imported compounds and reagents required for clinical diagnostics, chemistry and drug development. Several drug companies, including Roche and Aventis, said at the forum that they will discuss setting up joint ventures in drug development with Rusnano.

Russia's push into nanotech is part of its larger effort to strengthen basic science and education. The Kurchatov Institute, Russia's premier centre for nuclear physics, last year received more than 5.9 billion roubles from the government to set up a new centre for nano-, bio-, info- and cognitive sciences, including a state-of-the-art genome-sequencing facility, an upgraded synchrotron radiation machine and a new data-processing centre. And concrete plans exist for a national research centre for nanotechnology that includes the Kurchatov and several research centres run by the Russian Academy of Sciences.

But experts warn of exaggerated hopes. "Russia is throwing a lot of money and brain power at nanotechnology," says Ian Miles, an expert on technological innovation at the University of Manchester, UK. "But favourable conditions, from more favourable starting points, are being created everywhere. It's not going to be easy."

Quirin Schiermeier

See Editorial, page 1028

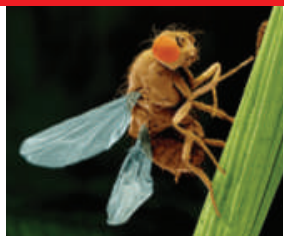

FLIES GET FRIGHT FROM FALSE MEMORIES Light activation pinpoints where learning happens in fruitflies.

go.nature.com/gMnKEv

\section{Hazy goals hold up conservation}

\section{CAPE TOWN}

With the world almost certain to miss a target to slow extinction rates by 2010 , governments are looking to adopt new biodiversity targets next year. What those might be - and what science will be needed to underpin them - is yet to be established, researchers said last week at a conference on biodiversity held in South Africa.

"2010 may not be the year when we reverse the rate of loss of biodiversity, but needs to be the year when we reversed the response to that loss," says Achim Steiner, executive director of the United Nations Environment Programme (UNEP).

In 2002, more than 120 countries adopted a target to achieve a "significant reduction" in the rate of biodiversity loss by 2010. That aim will not be met, says Georgina Mace, director of the Centre for Population Biology at Imperial College London. But just how much the world will miss the target by is difficult to calculate, because the target does not specify a baseline extinction rate from which to start counting. "The lack of baselines and timescales are quite problematic," Mace says.

The next generation of targets will aim for a more positive outcome and set more easily measurable goals, says David Cooper of the Convention on Biological Diversity secretariat in Montreal. The targets are likely to aim for a complete halt to biodiversity loss by 2050 , and to set more modest interim targets for 2020.

The new targets will be designed to encourage countries to address the underlying drivers of biodiversity loss, such as climate change and unsustainable land use, Cooper says. They will also recognize the socioeconomic value of 'biodiversity services', such as tourism revenue generated by coral reefs or the carbon sequestration value of a forest.

The new goals are being agreed through a set of international negotiations, to culminate in Japan in October 2010. There, governments will also consider whether to set up an Intergovernmental Platform on Biodiversity and Ecosystem Services to bridge the gap between science and policy.

Science advice is currently slow to reach policy-makers, says Steiner, and too piecemeal when it gets to them. "The number of scientific assessments, their focus and assumptions, are simply too bewildering and fragmented," he told the Cape Town conference.

Scientists also need to find better ways of estimating biodiversity loss, Mace says. Writing in Science last month, a team led by UNEP's Matt Walpole identified serious shortcomings in the indicators used to measure progress towards the 2010 target, such as monitoring changes in species' status on the International Union for Conservation of Nature's endangered 'red list' or in the size of protected areas. But the indicators do not include any measurement of the effects of climate change on biodiversity, and few address the societal benefits of safeguarding species (M. Walpole et al. Science 325, 1503-1504; 2009).

Cooper adds that scientists need to better integrate data to provide a more holistic

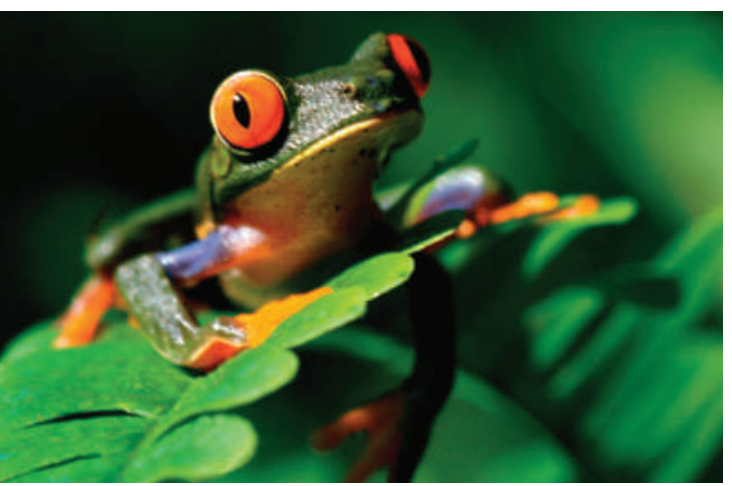

The red list names nearly 700 frogs and toads as 'endangered'.

picture of biodiversity trends. "We need to develop a monitoring system," he told Nature.

The Biodiversity Observation Network of the Group on Earth Observations offers such a system for 'joining the dots' of global biodiversity knowledge. Launched in 2008, the network aims to be a one-stop shop for information on biodiversity. It will release indicators, generate maps of priority areas, provide conservation plans and report on trends in uses of biological resources.

Chairman Bob Scholes, of South Africa's Council for Scientific and Industrial Research, says the network will start producing a "strong element" of this bigger picture in two to three years' time. Linda Nordling 